\title{
Multiple flowering of blackberry and its role in the formation of this crop harvest in the conditions of Central Russia
}

\author{
Lidia Gruner*, and Boris Kornilov \\ Russian Research Institute of Fruit Crop Breeding (VNIISPK), 302530, Orel, Russian Federation
}

\begin{abstract}
The materials of the article present data on the various manifestations of ability of repeated flowering and fruiting during one growing season by representatives of the subgenus Eubatus Focke (blackberry). The research was carried out in experimental plantings of the Russian Research Institute of Fruit Crop Breeding (city of Orel). Classical methods of cultivar study were used. Experimental blackberry cultivars have different maturation periods, so the delayed formation of peduncles is of unequal importance when growing them. In this regard, the purpose of the work was to study the phenomenon of multiple flowering and fruiting of blackberry in the conditions of the Orel region of Russia, to identify cultivars and breeding forms with the greatest severity of this trait, to show its positive and negative sides. As a result, it has been found that the ability of blackberries to flower repeatedly is a characteristic feature of this crop, and for a number of cultivars it is a valuable economic feature in the conditions of Central Russia. Three main types of this phenomenon are shown, which manifest themselves differently in the studied cultivars and forms. Based on the data obtained, we believe that early ripening blackberry cultivars are preferred for the middle part of Russia.
\end{abstract}

\section{Introduction}

Blackberry (subgenus Eubatus Focke of the genus Rubus L.) is one of the very plastic berry crops, with a wide range of adaptive mechanisms and reactions that enable it to adapt to various conditions of bio- and agro coenoses. By its ecological affiliation, it is a mesophyte [1-3]. Nevertheless, significant morphological diversity of wild species and cultivated cultivars, differences in their frost and drought resistance, high self-fertility and productivity, late flowering that protects flowers from spring frosts, special bush structure, ability to recover from various damage and the simplicity of vegetative reproduction - allow it to occupy extensive natural and cultural areas in many regions of the world $[4,5]$. The great breeding success in recent decades has led not only to an improvement in the quality of blackberry fruits, but also to a high resistance of modern cultivars to the most aggressive pathogens [6], which also increased the adaptive capabilities of the culture, including when introducing blackberry cultivars from the regions where they were created to other

\footnotetext{
* Corresponding author: gruner@vniispk.ru
} 
countries. Therefore, the cultivation of blackberry has become attractive for many gardeners both in large farms and in small plots of adjacent and suburban territories of various climatic zones.

Regular obtaining of a high-quality harvest is one of the main tasks when moving blackberry cultivars to regions with conditions that differ to varying degrees from optimal for their cultivation. The Orel region of Russia, where this work is being carried out, also belongs to such zones. Despite the fact that the weather factors of the growing season here are quite favorable for the growth and full fruiting of blackberry [7,8] winters are often accompanied by low (up to $-20 \ldots-30^{\circ} \mathrm{C}$ and below) negative temperatures, detrimental to most modern cultivars of this plant when cultivated without special cover [9, 10]. But even under such a cover, there are cases of significant freezing of their vegetative and generative organs [8]. In this regard, another important adaptive quality that allows blackberry to maintain a certain productivity even after significant damage to the aboveground part of plant is the ability of most representatives of this subgenus to repeatedly flower and bear fruit. V.L. Vitkovsky writes in detail about the manifestation of this feature in fruit and berry plants, in particular, in his works $[11,12]$. The author reports on the influence of any abnormal conditions (primarily weather) on its occurrence in most cases. As a result, undesirable flowering of various crops often occurs at atypical times for them, which weakens the plants, especially during autumn flowering and causes corresponding damage in the winter months.

According to our observations, for blackberries, the ability to repeatedly flowering is a fairly common phenomenon that probably occurs much more often than in other fruit and berry crops. Phenotypically it manifests in the formation of new peduncles after the terms of the major flowering. In this regard, we recall the structure of the blackberry bush. It consists of a perennial underground rhizome and an aboveground part, represented by two types of stems - vegetative annual (shoots of the current year) and generative - biennial. After crop ripening, the biennial stems die off, and they are replaced by wintering annuals, which buds, after differentiation, give flowers and fruits. Then the cycle repeats. At the same time, all the buds on a two-year-old stem are generative, although their degree of formation is different. The main zone of blackberry fruiting is usually the middle part of the stems, while the upper and lower thirds are usually less productive. Therefore, when cultivating cultivars of this crop and forming shoots, the apical part is usually removed, and in the lower part of the stems, the buds either do not awaken (especially with a heavy load in the middle zone), or they awaken later than the upper ones and provide longer flowering and fruiting of the cultivar. The exception is the remontant cultivars and forms, in which fruiting is localized mainly in the apical zone of the stem. Sometimes the lower buds of two-year-old stems are productive only in case of severe damage to the upper part of the bush, first of all - with severe winter freezing of plants. In this case, the fruits formed in the basal zone of the plant can partially compensate for crop losses. Moreover, the berries of the lower level of blackberry branches are usually larger than the upper one.

Fruiting on the shoots of the current year is another manifestation of multiple flowering and fruiting of blackberry and closely related raspberry [12-15, etc.]. It is of great value for the conditions of the central part of Russia, as it suggests the potential possibility of solving the problem of winter hardiness of blackberry. In the future, permanent flowering capacity can probably become the leading direction in creating the assortment of this crop in the specified region. There are not many such blackberry cultivars yet $[6,14$, etc.], but they are becoming more and more popular. Nevertheless, in zones similar in climatic conditions to the region of our study, they at best manage to form only a part of the berries of the autumn harvest. Therefore, to date, along with breeding for an earlier summer-autumn harvest of remontant forms and the creation of high-hardy cultivars with fruiting on biennial stems, it may also be relevant to identify forms prone to repeated abundant flowering and fruiting on 
stems of the second year of life, capable of giving a "safety" crop with full or partial loss of the main one, which has time to mature during the growing season. Such blackberry genotypes, for which the formation of fertile laterals in the basal part of the stem is the norm and occurs annually, are especially interesting from this point of view.

We note that often long peduncles coming from the base of the blackberry stem of the second year of life can be taken as a manifestation of permanent flowering capacity (flowering on the shoots of the current year). Nevertheless, this is a misconception, to which the main creator of the world's first remontant blackberry cultivars pays attention - J. R. Clark [14].

Thus, we assume that the ability of blackberry to flower and bear fruit repeatedly in the conditions of a cold climate for them in the middle zone, in some cases, can be considered as a positive economic feature and as an indicator of adaptability to unstable growing conditions.

In connection with the above, the purpose of this study was to study the phenomenon of multiple flowering and fruiting of blackberry in the conditions of the Orel region of Russia, to identify cultivars and breeding forms with the greatest severity of this trait, to show its positive and negative sides.

\section{Materials and Methods}

The research was carried out in the experimental plantings of the Department of Breeding and Cultivar Study of Berry Crops of the Russian Research Institute of Fruit Crop Breeding (VNIISPK) in 2018...2021. The objects of study were a number of introduced cultivars of different maturation periods, as well as breeding forms of blackberry obtained at VNIISPK - representatives of various morphological groups: erect, trailing and semi-erect/semitrailing. The plants are placed on the plot according to the scheme of $1.5 \times 4 \mathrm{~m}$. The experimental site is well cultivated and illuminated, protected from all sides by forest belts. Rows of experimental cultivars are located from north to south for maximum illumination of plants throughout the day. An espalier with a height of $1.3-1.5 \mathrm{~m}$ is used to tie the stems. In winter, the plants are covered with agrotextile with a density of $60 \mathrm{~g} / \mathrm{m}^{2}$ in one layer tied to espalier. In the winter of $2020 \ldots 2021$, most of the samples were covered with two layers of covering material, and the three most frost-resistant of them were not covered at all as an experiment. The cultivar study of blackberry was carried out according to the "Program and methodology of cultivar study..." [16]. Phenological observations were carried out to study the phenomenon of multiple flowering and fruiting of blackberry.

\section{Results and Discussion}

Since the ability to bloom and bear fruit repeatedly was especially evident during the study of the collection both in very favorable and, conversely, in particularly unfavorable winter weather conditions, we were able to identify three main types of this phenomenon in blackberry. The first type is two successive waves of flowering and fruiting, which are consistently manifested every year. The second type is the formation of single generative laterals in atypical terms for cultivars (after the main flowering and fruiting) and which is both a characteristic feature of a particular cultivar and occurs only under unfavorable conditions. The third type is flowering and fruiting on the shoots of the current year (permanent flowering capacity), which manifests annually as a varietal feature. 


\subsection{Blackberry forms that have two annual waves of flowering and fruiting}

In the course of phenological observations (Table 1), 2 breeding forms of blackberry were identified, yielding a regular harvest first in the upper part of the bush, then in the lower part. These are seedlings from free pollination of North American cultivars Cheynne and Black Satin. The data are given for 2019, when due to favorable weather conditions of both winter and summer periods, both waves of flowering and maturation of breeding forms were well expressed. It should be noted that the berries of these forms have a harmonious dessert taste with a predominance of sugars in them (the sugar-acid index is 12.7 in the seedling of Cheyenne and 14.2 in the seedling of Black Satin). Therefore, they attracted attention also from the point of view of the possibility of using them in breeding to improve the taste of fruits.

Table 1. The terms of flowering and maturation of breeding seedlings from free pollination of Cheyenne and Black Satin as well as Agawam and Thornfree zoned in Russia (2019).

\begin{tabular}{|l|c|c|c|c|}
\hline \multirow{2}{*}{ Genotype name } & \multicolumn{2}{|c|}{ flowering } & \multicolumn{2}{c|}{ maturation } \\
\cline { 2 - 5 } & mass & end & mass & end \\
\hline \multirow{3}{*}{$\begin{array}{l}\text { Seedling of Cheyenne } \\
\text { (open pol.) }\end{array}$} & 03.06 & 10.06 & 29.07 & 20.08 \\
\cline { 2 - 5 } & \multicolumn{4}{|c|}{ first wave } \\
\cline { 2 - 5 } & 18.06 & 18.07 & 20.08 & 15.09 \\
\hline \multirow{4}{*}{$\begin{array}{l}\text { Seedling of Black } \\
\text { Satin (open pol.) }\end{array}$} & 03.06 & 10.06 & 29.07 & 28.08 \\
\cline { 2 - 5 } & \multicolumn{4}{|c|}{ fecond wave } \\
\cline { 2 - 5 } & 18.06 & 18.07 & 28.08 & 09.09 \\
\hline Agawam & 29.05 & 07.06 & 29.07 & 06.08 \\
\hline Thornfree & 12.06 & 28.06 & 08.08 & 15.09 \\
\hline
\end{tabular}

The table shows that the mass flowering and maturation of the first wave berries in the identified breeding forms coincides with the mass flowering and maturation of the earliest cultivar Agawam. The mass flowering and maturation of the second wave was significantly later than that of the late Thornfree cultivar, while the end of the maturation of the second wave berries occurred simultaneously with this cultivar. That is, the maturation rate in both periods of crop formation turned out to be high, but the total duration of active fruiting of seedlings covered more than one and a half months. At the same time, all the berries had time to ripen.

In the winter of $2020 \ldots 2021$, these breeding forms were left experimentally without cover, taking into account their relatively high winter hardiness. Nevertheless, the weather conditions of that particular winter developed in a rather extreme way due to significant temperature changes. December 2020 was moderately cold with a temperature range from 1.2 to $-12^{\circ} \mathrm{C}$ throughout the month. Until mid-January 2021 , temperatures also remained at the same level. In the second half of January, a significant decrease began, reaching minimum values on January $18-20\left(-24 \ldots-25.6^{\circ} \mathrm{C}\right)$. During the coldest period of the month, the height of the snow cover was about $30 \mathrm{~cm}$, which was quite stable. On January 23, a sharp warming began (to small positive values), which lasted until the end of the month. February was the coldest month, with slight thaws at the beginning and end of the month, on the remaining days significant negative temperatures were kept round the clock, with a minimum on February $17-18$ ( -30 and $-28^{\circ} \mathrm{C}$, respectively). The snow cover those days was about $50 \mathrm{~cm}$. March began with small negative temperatures, and during the day the temperature rose to small positive values, while the snow layer decreased significantly. But by the end of the first decade of the month, there was a sharp drop in air temperature, which reached $-24^{\circ} \mathrm{C}$ on March 11. After that, on March 14, the temperature began to rise with a predominance of small negative indicators and positive values. 
Unstable winter temperatures and especially a sharp cooling after the thaw in March 2021 led to severe freezing of the above-mentioned breeding forms - up to 3.5-4 points on a 5 -point scale (up to $60-75 \%$ of the upper part of the stems). Nevertheless, in spring, each bush of these forms released 8-10 long peduncles from the remaining buds of the lower part of the stems (Figure 1), containing 25-40 flowers, from which berries were later formed. If we consider that the weight of these berries is about $4.5 \mathrm{~g}$, then the average yield from the bush was $1.2-1.5 \mathrm{~kg}$. At the same time, there was an active formation of replacement shoots that completely restored the bushes for a full-fledged harvest next year. That is, the ability to form generative shoots in the lower part of the stems in combination with good shoot formation can be regarded as a positive economic quality of the identified breeding forms.

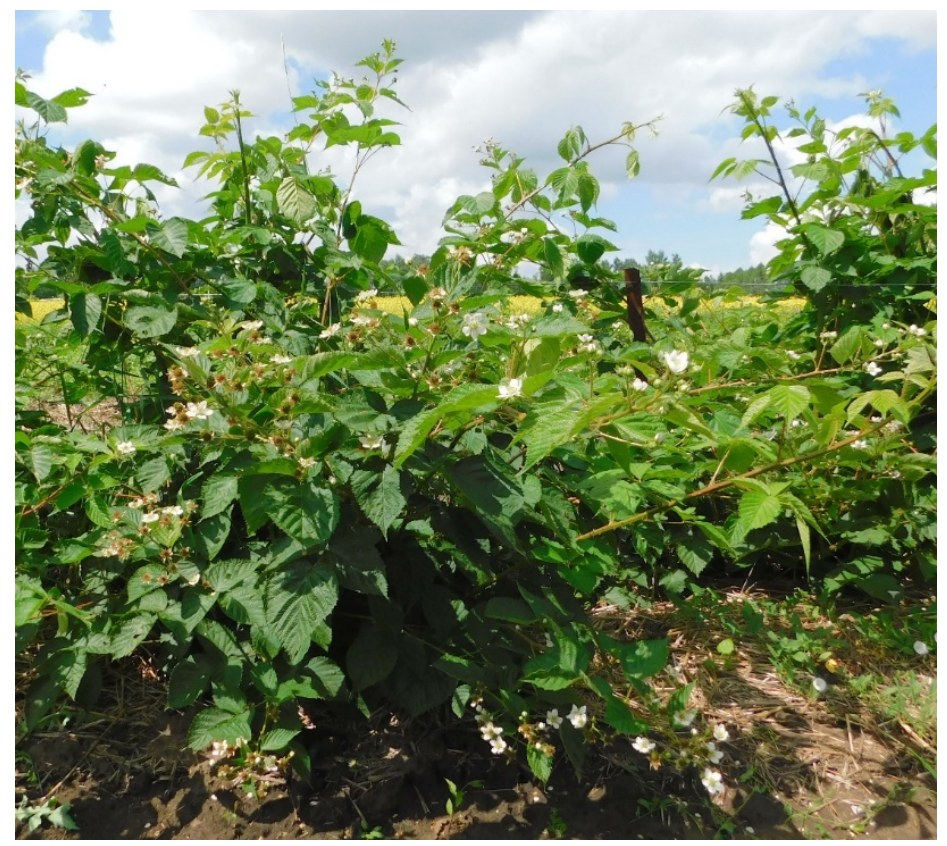

Fig. 1. Long $(1.5 \mathrm{~m})$ peduncles extending from the base of the Cheyenne blackberry seedling bush after severe freezing of the bush in the winter of 2020-2021.

All the plants of the blackberry collection that were under artificial shelter with agrotextile in the winter of $2020 \ldots 2021$, and especially those that were covered, in addition, with a layer of snow on top, overwintered well, with minimal damage or even without them.

\subsection{Cultivars and forms forming generative laterals in atypical terms (after the main flowering and fruiting)}

Among the studied blackberry cultivars and breeding seedlings with fruiting on stems of the second year (floricane-fruiting), flowering and fruiting at a time later than the main one were manifested to varying degrees during the years of study (Table 2). 
Table 2. Varietal differences in the degree of manifestation of delayed flowering and fruiting of blackberry at different periods of berry ripening (VNIISPK, 2018...2021).

\begin{tabular}{|c|c|c|c|c|}
\hline \multirow{2}{*}{$\begin{array}{l}\text { Cultivar, } \\
\text { form name }\end{array}$} & \multicolumn{4}{|c|}{ Degree of delayed flowering manifestation } \\
\hline & high $^{1}$ & medium $^{2}$ & weak $^{3}$ & absent $t^{4}$ \\
\hline \multicolumn{5}{|c|}{ cultivars and forms of early maturation } \\
\hline Agawam & & & & + \\
\hline Brzezina & & + & & \\
\hline Loch Tay & & & + & \\
\hline Natchez & & + & & \\
\hline Osage & & & + & \\
\hline $\begin{array}{l}\text { Seedling of the } \\
\text { Cheyenne cultivar }\end{array}$ & + & & & \\
\hline $\begin{array}{l}\text { Seedling of the Black } \\
\text { Satin cultivar }\end{array}$ & + & & & \\
\hline \multicolumn{5}{|c|}{ cultivars and forms of medium maturation period } \\
\hline Jumbo & & & + & \\
\hline Ouachita & & & + & \\
\hline El. seedling LN-4 & & & + & \\
\hline El. seedling LN-14 & & & + & \\
\hline $\begin{array}{l}\text { Thornfree } \times \mathrm{R} \text {. } \\
\text { caucasicus I seedling }\end{array}$ & & & & + \\
\hline \multicolumn{5}{|c|}{ late-ripening cultivars } \\
\hline Black Satin & & + & & \\
\hline Chester Thornless & & + & & \\
\hline Thornfree & & + & & \\
\hline Triple Crown & & + & & \\
\hline
\end{tabular}

Note: ${ }^{1}$ - annually with the formation of several laterals; ${ }^{2}$ - annually, single laterals,

${ }^{3}$ - in some years, single laterals; ${ }^{4}$ - usually does not form belated laterals

It follows from the Table that the first group with a high degree of delayed flowering includes the breeding forms already described above. In the cultivars and forms of the average ripening period, this feature is weakly manifested. In late-ripening cultivars- to medium degree. Only some of them (in this case, Agawam and the Thornfree $\times \mathrm{R}$. caucasicus I seedling) usually do not give such laterals. As our observations have shown, for early and medium-ripened cultivars and forms (Figure 2), this quality only contributes to an increase in crop weight and extension of the ripening period, but all the berries have time to fully ripen before the end of the season. For late-ripening cultivars it is undesirable when growing them in the middle zone of Russia, since it lengthens the terms of the already late crop ripening and in this regard can negatively affect the overwintering of plants. Therefore, the early ripening cultivars can be considered the most valuable for this zone. In late cultivars, it is better to remove late peduncles before berry formation. 


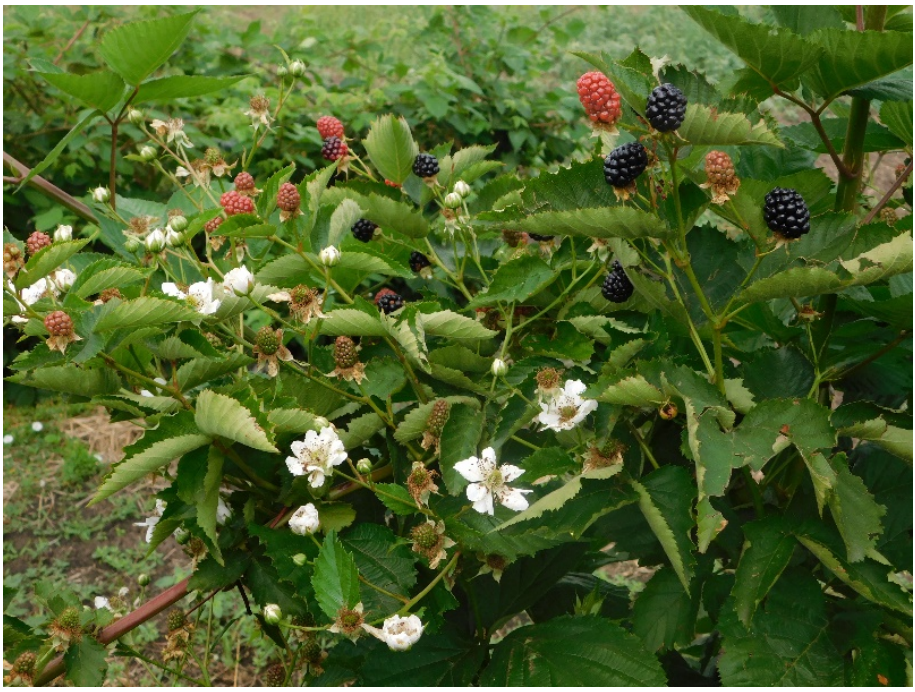

Fig. 2. Simultaneous flowering and ripening of Brzezina berries (2021, VNIISPK).

Nevertheless, all the studied cultivars and forms of blackberry form generative shoots in the basal zone of the stem of the second year of life with severe damage (including freezing) or removal of its upper sections. In this case, we leave them for fruiting only when at least 2-3 replacement shoots are formed in the bush to restore the bush and fruiting in the next season. If replacement shoots are not formed, the fruit branches are removed. This feature should also be considered, apparently, when laying blackberry cuttings and cutting out all growing generative laterals.

\subsection{Cultivars flowering and fruiting on the shoots of the current year (primocane-fruiting)}

Permanent flowering capacity is a special case of the manifestation of multiple blackberry flowering. This type of generative organ formation, although rare so far for blackberry, is genetically fixed in remontant cultivars, therefore it manifests annually. Cultivars of this type are able to flower and yield both on shoots of the current year and on biennial stems. Their first yield is early summer, the second is autumn. Despite the late ripening terms of berries of such cultivars on annual shoots, there is information about the possibility of shifting these terms towards earlier ones and increasing yields through various agricultural methods: pruning, using tunnel covers, special placement on a espalier, etc. [17, etc.]. In the VNIISPK collection, work with remontant cultivars has recently begun, but most of the remontant cultivars of the world assortment ( 7 cultivars) have already been collected. Despite the fact that the plants are 1 year old, some differences between the cultivars in terms of autumn flowering are already noticeable, which opens up prospects for breeding to create more early-maturing cultivars and their economic use in the conditions of the central regions of Russia.

\section{Conclusion}

Consequently, the ability of blackberry to flower repeatedly is a characteristic feature of this plant and a valuable economic feature in central Russia. During the study, three main types of this phenomenon were noted, available in different cultivars and forms. The first type is represented by two successive waves of flowering and fruiting. The second one is 
associated with the formation of single generative laterals in atypical terms for cultivars (after the main flowering and fruiting), prolonging the fruiting period. The third type is characterized by flowering and fruiting on the shoots of the current and last years (permanent flowering capacity). The first and third types appear annually and are a stable trait. The second type is less stable and occurs sporadically and not in all plants of a particular cultivar. For the cultivars of early and medium maturation periods, additional inflorescences that have arisen after the main flowering lengthen the ripening period of berries. At the same time, all the fruits have time to ripen before the end of the season in the conditions of the center of our country. For late-ripening cultivars in this region, the formation of late peduncles is an undesirable phenomenon, and they should be removed before the formation of berries. After severe damage to plants in winter, a crop may be laid in the lower zone of the stem, which is permissible to leave only when replacement shoots are formed. Based on the data obtained, we believe that early ripening cultivars are preferred for the middle part of Russia, which, even with late flowering, finish bearing fruit before the end of the summer period and have time to prepare for overwintering.

\section{References}

1. S. V. Yuzepchuk, Flora of the USSR M.-L., 8, 21-58 (1941) (In Russian)

2. A. A. Grossgeim, Flora of the Caucasus M.-L. 5, 44-58 (1952) (In Russian)

3. N. L. Neronova, Proceedings on Applied Botany, Genetics, and Breeding L. 50(3), 103-107 (1973) (in Russian)

4. V. L. Vitkovskiy, Raspberry and blackberry, Fruit Plants of the World, 355-382 (S.Pb. M. Krasnodar, 2003) (in Russian)]

5. B. C. Strik, C. E. Finn, J. R. Clark, P. Bañados, Acta Horticulturae 777, 209-218 (2008) DOI: 10.17660/ActaHortic.2008.777.31

6. J. R. Clark, C. E. Finn, Global Science Books (Fruit, Vegetable and Cereal Science and Biotechnology) 5, 27-43 (2011)

7. Agroclimatic Reference Book of the Orel Region, 6-10 (L.: Gidro meteoizdat Publ, 1960) (in Russian)]

8. L. A. Gruner, Contemporary Horticulture 3, 27-41 (2019) DOI 10.24411/2312-67012019-10305 (in Russian)

9. S. N. Evdokimenko, V. L. Kulagina Horticulture and Viticulture 4, 20-23, (2015) (in Russian)

10. Yu. Yu. Telepenko, Plant Cultivars Studying and Protection 14(1), 124-131 (2018) DOI 10.21498/2518-1017.14.1.2018.126521 (in Ukrainian)

11. V. L. Vitkovskiy, Agricultural Science Bulletin 3, 99-105 (1965) (in Russian)

12. V. L. Vitkovskiy, Morphogenesis of fruit plants, 199 (L.: Kolos, 1984) (in Russian)

13. I. V. Kazakov, S. N. Evdokimenko, Remontant Raspberry, 288 (M., 2007) (in Russian)

14. J. R. Clark, HortScience 43(6), 1637-1639 (2008) DOI 10.21273/hortsci.43.6.1637

15. J. R. Clark, HortScience 49(8), 1097-1101 (2014) DOI 10.21273/ HORTSCI.49.8.1097.

16. I. V. Kazakov, L. A. Gruner, V. V. Kichina, Program and methods of fruit, berry and nut cultivars study (Orel) pp 374-395 (1999) (In Russian)

17. J. R. Clark, Ch. E. Finn, B. C. Strik, E. Thompson, Acta Hortic 926, 387-392 (2012) DOI 10.17660/ActaHortic. 2012.926.54 